\title{
'Emotional' does not even start to cover it: Generalization of overeating in emotional eaters
}

Citation for published version (APA):

Bongers, P., de Graaff, A., \& Jansen, A. (2016). 'Emotional' does not even start to cover it: Generalization of overeating in emotional eaters. Appetite, 96, 611-616. https://doi.org/10.1016/j.appet.2015.11.004

Document status and date:

Published: 01/01/2016

DOI:

10.1016/j.appet.2015.11.004

Document Version:

Accepted author manuscript (Peer reviewed / editorial board version)

Document license:

CC BY-NC-ND

\section{Please check the document version of this publication:}

- A submitted manuscript is the version of the article upon submission and before peer-review. There can be important differences between the submitted version and the official published version of record.

People interested in the research are advised to contact the author for the final version of the publication, or visit the DOI to the publisher's website.

- The final author version and the galley proof are versions of the publication after peer review.

- The final published version features the final layout of the paper including the volume, issue and page numbers.

Link to publication

\footnotetext{
General rights rights.

- You may freely distribute the URL identifying the publication in the public portal. please follow below link for the End User Agreement:

www.umlib.nl/taverne-license

Take down policy

If you believe that this document breaches copyright please contact us at:

repository@maastrichtuniversity.nl

providing details and we will investigate your claim.
}

Copyright and moral rights for the publications made accessible in the public portal are retained by the authors and/or other copyright owners and it is a condition of accessing publications that users recognise and abide by the legal requirements associated with these

- Users may download and print one copy of any publication from the public portal for the purpose of private study or research.

- You may not further distribute the material or use it for any profit-making activity or commercial gain

If the publication is distributed under the terms of Article $25 \mathrm{fa}$ of the Dutch Copyright Act, indicated by the "Taverne" license above, 


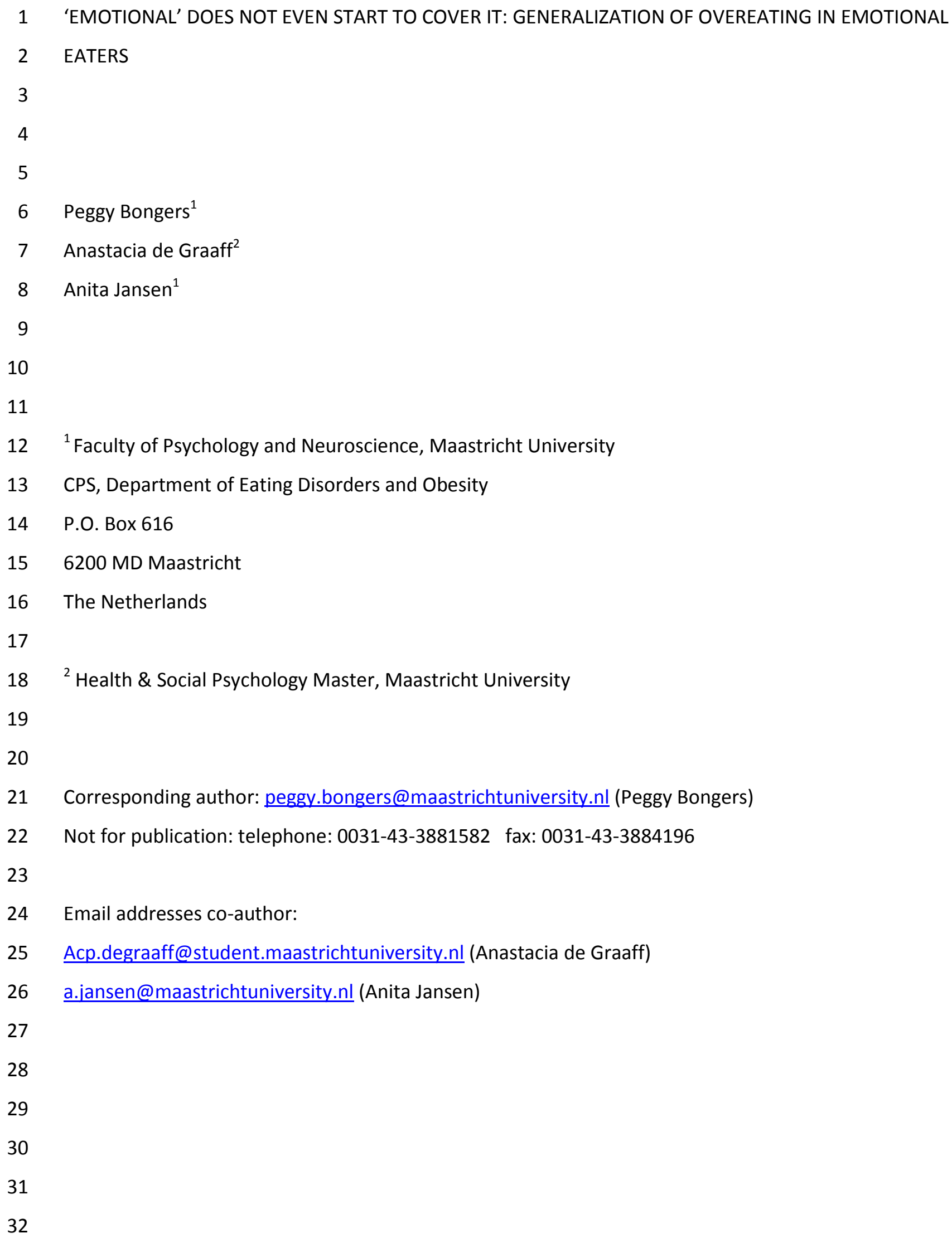


Based on recent studies indicating that emotional eating is not the clearly defined problem it is often

34 thought to be, the present study investigated whether emotional eaters overeat merely in response to

35 negative emotional cues, or to other cues as well. It was hypothesized that emotional eaters would

36 overeat after a variety of food cues, not limited to negative emotions. Participants took part in four

37 conditions (negative mood manipulation, positive mood manipulation, food exposure and a control

38 condition) divided over two sessions. Each condition was followed by a bogus taste test, after which

39 food intake was measured. Results showed strong correlations between food intake after all four

40 conditions, indicating that increased intake after one type of cue is related to increased intake after

41 other cues. Participants were identified as emotional or non-emotional eaters based on food intake in

42 the negative mood condition, and based on self-reported emotional eating scores. Both measures of

43 emotional eating were significantly related to food intake after all cues. Based on the current findings,

44 we conclude that individuals who show increased food intake when in a negative emotional state also

45 overeat when experiencing other food-signalling cues. This indicates that 'emotional eating' may not

46 fully capture the eating behaviour of individuals currently identified as 'emotional eaters'.

47

48

49 Keywords: emotional eating, external eating, food cue exposure, cue-reactive eaters, cue reactivity, food 50 intake, types of eaters 
51 In eating research, it is common practice to use labels to define certain types of eaters. In the 1970s,

52 Herman and Mack (1975) introduced the 'restrained eater', a term that is used to describe individuals

53 who deliberately try to restrict their food intake to maintain or achieve their desired weight. Restrained

54 eaters were later contrasted with disinhibited eaters (Stunkard \& Messick, 1985), to discriminate

55 between those who are constantly able to restrict food intake, and those who tend to overeat or break

56 their diets on a regular basis (Herman \& Polivy, 1975). Such disinhibiting factors leading to overeating

57 could be internal cues (e.g., emotions), or external cues (e.g., the sight or smell of food), and two types of eaters have been presented accordingly: emotional eaters (assumed to be specifically responsive to negative emotions) and external eaters (assumed to be specifically responsive to external food cues) (Van Strien, Frijters, Bergers, \& Defares, 1986). These eater types are distinguished from restrained eaters, who are supposed to succeed in restraining their food intake (Van Strien, et al., 1986). Currently, the distinction between emotional, external and restrained eaters is generally accepted, and the past 20 years have seen a wealth of studies devoted to these specific subtypes. Some clear empirical predictions follow from the division into these three eating types: individuals scoring high on measures of emotional eating should increase their food intake in response to the experience of (negative) emotions, high scorers on external eating scales should consume more in response to external cues, and those scoring high on restraint - but low on emotional and external eating- should not overeat.

However, recently there have been indications that emotional and external eating are not the clearly demarcated issues of overeating in response to negative emotions or external cues they have long been thought to be, but rather small aspects of a more general issue revolving around problematic food intake. Van Strien and Ouwens (2003) found that emotional eating, but not external eating or dietary restraint, moderated the relationship between a preload and food intake. Jansen, et al. (2011) assessed degree of emotional eating, external eating and restrained eating in a female student sample. Unexpectedly, external eating scores did not predict food intake after exposure to food, and very similar eating patterns among high scorers on all three types of eating were found. Based on their data, Jansen, et al. (2011) argued that there may be no need to distinguish between different types of eaters, but that high scorers on such scales are 'generally eating-concerned', whereas low scorers are unconcerned. According to the researchers, the eating-concerned individuals are characterized by an ever-present concern about their food intake as well as problems with restricting their food intake when confronted with intake-inducing cues such as emotions and palatable food. Along similar lines, studies taking a diary-approach were unable to relate emotional eating scores to food intake after the experience of daily hassles (Adriaanse, de Ridder, \& Evers, 2011; Conner, Fitter, \& Fletcher, 1999). However, they did 
identify snacking out of habit, restraint, and external eating as predictors of overeating after experiencing negative emotions. In an additional study, Adriaanse, et al. (2011; study 3) found that high scores on emotional eating were predictive of eating concerns, specifically high worrying about and high monitoring of their own eating behaviour, low perceived control over the own eating behaviour, and stronger extrinsic motivation with regard to healthy eating. They proposed that people who score high on emotional eating are preoccupied with food and eating in general, and focus specifically on the negative aspects of eating.
Considering the aforementioned studies, it is conceivable that there is a bigger issue of general food responsiveness at hand and that in certain individuals many different cues will lead to overeating. This idea is further supported by studies showing strong associations between self-reported emotional eating, external eating, and dietary restraint (Jansen, et al., 2011; Turner, Luszczynska, Warner, \& Schwarzer, 2010; Van Strien, et al., 1986). In addition, there is some evidence that positive emotions can also induce overeating (i.e., higher intake in an experimental compared to a control procedure) in people who score high on an emotional eating questionnaire (Bongers, Jansen, Havermans, Roefs, \& Nederkoorn, 2013a). Insight into the cues that lead to overeating and whether individuals who report or display excessive food intake do so in response to only one specific cue or several cues is important for more effective prevention, assessment, and treatment of overeating.

The aim of the current study was to investigate food intake of emotional eaters in response to a variety of potentially food-signalling cues. Because substantially more studies have focused on emotional compared to external eating and some previous studies have questioned the validity of emotional eating questionnaires and classifications (see for example Adriaanse, et al., 2011; Bongers, et al., 2013a; Evers, de Ridder, \& Adriaanse, 2009), we use emotional eating as the reference point in this study. In addition, because recent studies have shown that high scores on questionnaires assessing eating after negative emotions do not necessarily correspond with actual eating behaviour after negative emotions (Adriaanse, et al., 2011; Bongers, et al., 2013a; Bongers, Jansen, Houben, \& Roefs, 2013b; Brogan \& Hevey, 2013; Conner, et al., 1999; Evers, et al., 2009), we sought to add to self-report questionnaires by including actual food intake after experiencing negative emotions to identify emotional and non-emotional eaters.

It is hypothesized that participants identified as emotional eaters will consume more food in a negative emotional state, in a positive emotional state and after food cue exposure compared to a control condition. No intake differences between conditions in the non-emotional eaters are expected. 
114 In addition, it is hypothesized that emotional eaters will consume more food than non-emotional eaters 115 after all experimental conditions, but not the control condition.

\section{Methods}

\section{Participants}

121 Participants were 42 female undergraduate students of Maastricht University, ranging in age from 19 to

12227 years old $(M=20.26, S D=1.82)$. They were recruited through advertisements distributed throughout 123 the university and online. The advertisements called for female undergraduate students in the ages 18 124 to 30 to participate in a study allegedly on taste perception under different circumstances. Students 125 suffering from food allergies were excluded from participating. The study was approved by the local 126 ethics committee.

\section{Conditions and manipulations}

129 The study employed a within-subject design, with participants partaking in all five conditions. The conditions were divided over two sessions one week apart, with each session containing one control condition and one emotional condition. The emotional conditions were divided over the two sessions to 132 avoid difficulties in switching from positive to negative moods or vice versa in a short time-frame. One

133 control condition was implemented in each session to check for increased food intake during the second 134 session, in light of the possibility that participants felt more comfortable to eat upon returning to the 135 lab. The exposure condition always took place in the first session. Order of the emotion conditions and 136 of the conditions within sessions was counterbalanced. The conditions and sessions are depicted in 137 Table 1.

$138 \quad$ Negative mood. While listening to personal sad music (see procedure), participants wrote down a sad memory. If they were to finish writing before the music ended, they were instructed to keep thinking about the sad memory. The manipulation lasted for 5 minutes, and was proven to be effective in earlier 141 studies (Bongers, Van den Akker, Havermans, \& Jansen, submitted; Vuoskoski \& Eerola, 2012).

142 Positive mood. This procedure was similar to the negative mood induction, except that participants 143 listened to a personal happy piece of music, while thinking of and writing down a happy memory. 144 Food exposure. Participants were presented with two bowls containing two varieties of one of their top 3 chosen foods (e.g., for chocolate, they would receive M\&M's and Maltesers). For 3 minutes, they 
were instructed by the experimenter to smell the food and think about eating it, but not to actually eat it.

Control. In the control condition, participants solved connect-the-dots puzzles for 5 minutes. The puzzles ranged from 118 to 270 dots.

Table 1. Overview of conditions per session.

\begin{tabular}{|c|c|}
\hline Conditions in Session 1 (week 1$)^{1}$ & Conditions in Session 2 (week 2) \\
\hline Negative or Positive & Negative or Positive $^{2}$ \\
\hline Exposure & Control \\
\hline Control & \\
\hline
\end{tabular}

\section{Measurements}

Manipulation check. To evaluate successfulness of the manipulations, participants filled out four $100 \mathrm{~mm}$ VAS scales before and after every manipulation. The VAS scales asked how sad, happy and hungry the participant felt, as well as how strong their desire to eat was. The scales ranged from 'not at all' to 'very much' for the measures of sadness, happiness and hunger, and from 'not strong at all' to 'very strong' for the desire-measure.

163 Food intake. Participants were presented with three types of food which they had selected as their favourites from five types of food before the start of the experiment. This selection was included to ensure food liking. For each type of food, two varieties were presented, as studies have shown that food variety counters sensory specific satiety (Brondel, et al., 2009; Hetherington, Foster, Newman, Anderson, \& Norton, 2006). The types of food and their varieties (kcal per 100 grams reported in brackets) were: Chocolate - M\&M's (479 kcal) and Maltesers (498 kcal); Crisps - salty (555 kcal) and paprika (560 kcal); Peanuts - salted peanuts (615 kcal) and cocktail nuts (535 kcal); Cookies - mini chocolate chip cookies (505 kcal) and typical Dutch mini syrup waffles (445 kcal); Sweets - gummy bears

171 (328 kcal) and gummy cola bottles (343 kcal). Food was presented in large bowls, containing between

172553.97 grams ( $S D=15.92$; for crisps) and 1007.16 grams ( $S D=96.10$; for $M \& M s)$ of each food. For each

173 participant, the top three foods were counterbalanced over conditions. The two control conditions and

174 the two emotional conditions were paired with the same type of food (i.e., if a participant received

175 chocolate during the first control condition, she received chocolate during the second control condition 
taste test as well). Participants filled out questions regarding the chosen foods during the bogus taste tests, which took place after every manipulation. Questions were asked about the palatability of the food, the flavour, and how the two food varieties compared to each other. Participants were instructed to taste of each food variety in order to answer the questions, and they were told that they were free to eat as much as they liked. Each taste test lasted for 5 minutes. Actual food intake was measured by weighing the bowls with food in a separate room before and after each taste test.

Dutch Eating Behaviour Questionnaire (DEBQ). The DEBQ (Van Strien, 2005) is a 33-item self-report questionnaire measuring dietary restraint (DR; 10 items), external eating behaviour (EX; 10 items) and emotional eating behaviour (EE; 13 items). Questions are answered on a 5-point Likert Scale, ranging from 'never' to 'very often'. A mean score per subscale is calculated. Although the DEBQ has high internal consistency and factorial validity (Van Strien, et al., 1986), the predictive and discriminant validity of the external (Jansen, et al., 2011) and emotional subscales (Bongers, et al., 2013a; Evers, et al., 2009) is debatable.

Awareness check. A questionnaire was used to check whether participants were aware of the hypothesis of the study and whether they complied with the instruction to not eat in the 2 hours prior to the experiment.

$B M I$. BMI was obtained by measuring and weighing participants in the lab, while wearing street clothes and no shoes.

\section{Procedure}

Participants signed up for participation in a study on the palatability of food. They were instructed by email not to eat two hours prior to the experiment, and asked to rank five types of food (chocolate, crisps, peanuts, cookies, sweets) from most to least palatable. In addition, they were requested to fill out the DEBQ and to email back the completed questionnaire. Finally, they were asked to bring two songs that made them sad and two songs that made them happy with them to the lab on both testing days. Then dates for the first and second session were agreed upon. Upon entering the lab for the first session, the participant filled out an informed consent form and was informed about the procedure, using a cover story of taste perception under different circumstances. Then, the first mood VAS was filled out, followed by one of the manipulations (either negative or positive emotion, exposure, or control). The experimenter left the room during all manipulations, except for the exposure. After the manipulation, the participant was provided with another mood VAS. Subsequently, she was presented with two chosen bowls of food and filled out the taste questionnaire. The experimenter left the room 
during the 5 minutes of the taste test. Upon return, the experimenter took away the bowls of food and the participant relaxed for five minutes to make sure the effects of the manipulation and taste test would subside. Several magazines on gardening and home decoration were provided, carefully checked for the presence of eating-related advertisements or other food cues; whenever food was found in the magazines, the particular page was taken out. After relaxation, the exact same procedure was repeated for the other two manipulations. At the end, participants filled out a question regarding adherence to food intake restrictions, and the date for the second session was confirmed. The second session took place one week later, at the same time of day. The procedure was exactly the same as in the first session. The participant underwent the manipulation for the emotional condition opposite to the one in the previous session and a control condition. This order was counterbalanced across participants. At the end of the second session, the participant filled out the awareness check and height and weight were determined. Upon completion of the experiment, the participant was rewarded with course credits or a $€ 15$ voucher.

\section{Statistical analyses}

All intake data was converted from grams to kcal, and all analyses on intake use kcal consumed as the dependent variable. Intake in the two control conditions did not differ significantly (Control 1, $M=$ 169.02, $S D=105.81 ;$ Control $2, M=181.31, S D=119.31, t(41)=.76, p=.46)$, therefore one averaged variable of intake for the control condition was calculated and used in all analyses. Repeated Measures (M)ANOVAs with an adjusted alpha of .01 to correct for multiple testing were used to assess the effectiveness of the four manipulations (negative mood, positive mood, exposure and control). Pearson correlation coefficients were computed to assess associations between intake in different conditions. To analyze data with regard to the specific hypotheses, a Repeated Measures ANOVA with intake per condition (positive, exposure and control) as WS-factor and Z-transformed intake after negative emotions as covariate was conducted. A similar analysis was performed concerning Z-transformed selfreported emotional eating scores as covariate, with the addition of intake after negative emotions to the WS-factor. Greenhouse-Geisser corrections are reported whenever Mauchly's test indicated a violation of sphericity. Significant interactions were further investigated through spotlight analyses, in which intake was assessed at 1 SD below and 1 SD above the mean of emotional eating. 


\section{$\underline{\text { Results }}$}

$241 \underline{\text { General }}$

242

243 Participant characteristics

244 Participants' BMI ranged from 17.48 to $25.51(M=21.83, S D=2.14)$. DEBQ-EE scores ranged from 1.15

245 to $4.23(M=2.46, S D=.68)$. Compared to DEBQ-EE norm scores for female students (2.61-2.66; Van

246 Strien, 2005), the mean score is slightly below average. The awareness check revealed that none of the

247 participants was aware of the hypotheses of the study.

248

\section{Manipulations}

250 Four separate Repeated Measures (M)ANOVAs (WS-factor Condition: negative mood, positive mood, 251 exposure and control) were conducted to assess changes in sadness, happiness, hunger and desire to 252 eat in all five conditions. To correct for multiple testing across the five conditions, an alpha of .01 was 253 applied to these analyses. The results are reported in Table 2. From the analyses it is clear that all 254 manipulations were successful in reaching the intended effects (marked in grey). However, there was 255 also a significant decrease in hunger and desire in the negative mood, and a small but significant 256 increase in desire to eat during the second control condition. The effect of the negative mood 257 manipulation on hunger and desire is not surprising as this is a normal response to aversive states, 258 resulting from decreased gut activity (Wardle, 1990). 
Table 2. Mean and SD of VAS ratings before and after manipulation for each condition

\begin{tabular}{|c|c|c|c|c|c|c|c|c|}
\hline \multirow[b]{2}{*}{ Condition } & & \multicolumn{2}{|c|}{ Before manipulation } & \multicolumn{2}{|c|}{ After manipulation } & \multirow[b]{2}{*}{$F$} & \multirow[b]{2}{*}{$P^{1}$} & \multirow[b]{2}{*}{$\eta^{2}$} \\
\hline & & $M$ & $S D$ & $M$ & $S D$ & & & \\
\hline \multirow[t]{4}{*}{ Negative mood } & $\mathrm{Sad}^{2}$ & 13.74 & 16.31 & 52.55 & 21.25 & 120.21 & .000 & .75 \\
\hline & Happy & 64.48 & 13.29 & 37.60 & 16.44 & 145.12 & .000 & .78 \\
\hline & Hungry & 55.62 & 19.01 & 44.50 & 19.11 & 26.76 & .000 & .39 \\
\hline & Desire & 60.45 & 17.76 & 44.60 & 22.12 & 29.38 & .000 & .42 \\
\hline \multirow[t]{4}{*}{ Positive mood } & Sad & 14.71 & 14.54 & 9.88 & 12.09 & 12.76 & .001 & .24 \\
\hline & Happy & 66.62 & 10.01 & 77.86 & 11.70 & 94.08 & .000 & .70 \\
\hline & Hungry & 52.14 & 20.47 & 53.07 & 20.59 & .50 & .48 & - \\
\hline & Desire & 56.83 & 17.35 & 57.24 & 18.54 & .05 & .83 & - \\
\hline \multirow[t]{4}{*}{ Food exposure } & Sad & 17.38 & 18.49 & 15.50 & 16.04 & 4.34 & .04 & - \\
\hline & Happy & 63.93 & 13.63 & 66.95 & 12.46 & 3.43 & .07 & - \\
\hline & Hungry & 49.10 & 23.66 & 54.21 & 22.52 & 11.17 & .002 & .21 \\
\hline & Desire & 52.69 & 20.75 & 64.48 & 19.92 & 25.62 & .000 & .38 \\
\hline \multirow[t]{4}{*}{ Control 1} & Sad & 16.86 & 16.74 & 15.21 & 15.92 & 2.77 & .10 & - \\
\hline & Happy & 65.74 & 11.36 & 68.95 & 10.98 & 5.84 & .02 & - \\
\hline & Hungry & 51.71 & 21.30 & 52.86 & 23.58 & .70 & .41 & - \\
\hline & Desire & 52.90 & 17.05 & 52.79 & 19.65 & .006 & .94 & - \\
\hline \multirow[t]{4}{*}{ Control 2} & Sad & 19.07 & 20.06 & 17.38 & 16.91 & 1.55 & .22 & - \\
\hline & Happy & 63.50 & 15.52 & 64.38 & 14.15 & .28 & .60 & - \\
\hline & Hungry & 55.98 & 18.31 & 55.74 & 19.78 & .04 & .84 & - \\
\hline & Desire & 56.93 & 20.50 & 60.14 & 20.43 & 7.59 & .009 & .15 \\
\hline
\end{tabular}

${ }^{1}$ An $\alpha$ of .01 was used to correct for multiple testing

$262{ }^{2}$ The highlighted data (grey) reflect the intended effects of the various manipulations

263

264 Intake within sessions

265 Participating in multiple taste tests within one session did not appear to affect food intake. Repeated

266 Measures ANOVA showed that both within session 1 (test $1, M=136.46, S D=89.70$; test 2, $M=151.62$,

$267 S D=80.41$, test $3, M=163.82, S D=97.12, F(2,82)=1.96, p=.15)$ and within session 2 (test $1, M=$

$268165.91, S D=104.63$, test $2, M=180.77, S D=110.04, F(1,41)=.76, p=.39)$ the average amount of kcal

269 consumed per taste test was equal. 
271 Emotional eating - Actual consumption

272

273 Correlations

274 Food intake in a negative mood correlated significantly with food intake in a positive mood $(r=.87, p<$.

275 001), food intake after food exposure $(r=.53, p<.001)$ and food intake after a control procedure $(r=$

$276.48, p=.001)$. Thus, in line with our hypothesis, increased food intake after negative mood is strongly

277 related to increases in food intake after a positive mood and intake after exposure. Unexpectedly, there

278 was also a strong correlation between the negative mood and the control condition.

279

280 Food intake

281 The Repeated Measures ANOVA revealed a significant Condition X Emotional Eating interaction, $F$ (1.74, $28267.66)=3.88, p=.031, \eta^{2}=.08$, as well as a significant effect of Emotional Eating, $F(1,39)=54.63, p<$ $283.001, \eta^{2}=.58$. Pairwise comparisons with Bonferroni correction at 1 SD below (i.e., non-emotional 284 eaters) and 1 SD above (i.e., emotional eaters) the mean of emotional eating showed no condition 285 differences in non-emotional eaters (Positive Mood: $M=82.87, S E=9.64$; Exposure: $M=100.13, S E=$ 286 14.46; Control: $M=128.33, S E=20.12$; all $p$ 's $>.14)$. In the emotional eaters, intake in both the positive $287 \operatorname{mood}(M=234.58, S E=9.44 ; p=1.0)$ and exposure $(M=179.66, S E=14.16 ; p=.096)$ conditions did not 288 differ from intake in the control condition $(M=222.81, S E=19.71)$. There was however a significant 289 intake difference between the positive mood and exposure conditions, $p=.003$. Results are displayed in

290 Figure 1. These findings indicate that emotional eaters (based on actual consumption) show overall

291 increased food intake compared to non-emotional eaters, with intake differing across conditions only in 292 the emotional eaters.

293

$<<$ Insert Figure 1 about here $>>$

295

296

Figure 1. Caloric intake of emotional (1 SD above the mean) and non-emotional eaters (1 SD below the 297 mean), based on actual consumption, in the positive mood, exposure and control conditions. 
There were small but non-significant correlations between the DEBQ-EE and the other DEBQ subscales (EE - EX, $r=.21, p=.18 ; \mathrm{EE}-\mathrm{RS}, r=.26, p=.10)$. Self-reported emotional eating scores correlated significantly with intake in all conditions (negative mood, $r=.32, p<.042$; positive mood, $r=.32, p<$ .041 ; exposure, $r=.31, p<.047$; control, $r=.31, p<.047)$.

\section{Food intake}

The Repeated Measures ANOVA showed no significant Condition X Emotional Eating interaction, F (2.14, $83.62)=.08, p=.93$, nor a main effect of Condition, $F(2.14,83.62)=2.31, p=.10$. There was however a significant effect of Emotional Eating, $F(1,39)=6.30, p=.016, \eta^{2}=.16$. Results are plotted in Figure 2. These data show that self-reported emotional eating scores are significantly related to increased food intake in all conditions, i.e. after a variety of cues.

$$
<<\text { Insert Figure } 2 \text { about here }>>
$$

Figure 2. Caloric intake of self-reported emotional (1 SD above the mean) and non-emotional eaters (1 SD below the mean) in the negative mood, positive mood, exposure and control conditions

\section{Discussion}

In the current study we aimed to investigate whether people who overeat after experiencing negative emotions (based on both self-report and actual intake) are not merely emotional eaters, but instead overeat after a variety of food cues. The high correlations among intake during negative emotions, positive emotions, and after food exposure support this idea: increased intake after negative emotions is associated with increased intake in response to other cues, both in self-reported emotional eaters and emotional eaters identified by actual food intake. In addition to this, we also made predictions with regard to emotional versus non-emotional eaters. More specifically, we expected emotional eaters to show increased food intake in every experimental condition compared to the control condition, while we expected no differences in food intake in any of the conditions in the non-emotional eaters. Furthermore, we hypothesized that in all experimental conditions, but not the control condition, emotional eaters would consume more food than non-emotional eaters. The latter prediction was partly confirmed: emotional eaters tended to consume more food in all conditions, including the control 
condition. With regard to the first hypothesis, as predicted, the non-emotional eaters consumed equal amounts of food under all circumstances. However, the emotional eaters - at least when identified on basis of their intake - consumed more food in the positive mood than in the exposure condition, but neither condition differed from control. The data are in line with studies that show a strong correlation between questionnaire scores on emotional and external eating (Jansen, et al., 2011; Turner, et al., 2010; Van Strien, et al., 1986) and studies that have shown increased food intake in response to positive emotions in emotional eaters (Bongers, et al., 2013a). Furthermore, a recently published study (Vainik,

341 Neseliler, Konstabel, Fellows, \& Dagher, 2015) showed that various eating related traits, including 342 emotional eating, (i.e., emotional eating, attention paid to food, control over eating, eating impulsivity 343 and binge eating) all share a similar underlying construct, which the researchers labelled 'uncontrolled 344 eating'. With regard to intake in emotional eaters, the data show that self-reported emotional eaters consumed more food than non-emotional eaters in response to all cues. Emotional eaters classified on their actual intake also overeat in response to all cues, albeit to a lesser degree after exposure compared to when in a positive mood. It might be that food exposure is a different construct from emotions and does not lead to the same intake patterns. If so, however, it could be argued that the nonemotional control condition should also have led to different intake levels, and this was not observed. Together, the findings suggest that high levels of emotional eating are indicative of increased food consumption in general, and not specifically in response to negative emotions.

Interestingly, we also found high correlations between the experimental and control conditions and the control procedure seemed to elicit the exact same behaviour in participants as our experimental procedures did. One possibility is that certain individuals (i.e., those identified as emotional eaters) always eat more than other individuals (i.e., non-emotional eaters), no matter what the circumstances are. The mere presence of food during the taste test after the control condition was already enough to trigger increased intake. However, similar control conditions (i.e., taste test without a preceding manipulation) have been used numerous times without leading to an increase in food intake. On the other hand, it is also conceivable that the control condition might have unintentionally served as a fourth experimental condition: the knowledge that eating of high-caloric food would be necessary as a participant in the experiment, or having already consumed food in a condition preceding the control condition, could have served as triggers for eating. Similarly, it is possible that the puzzles we used caused boredom, ego depletion, stress, or feelings of disappointment or inadequacy, which could also all act to induce overeating (Greeno \& Wing, 1994; Groesz, et al., 2012; Havermans, Vancleef, Kalamatianos, \& Nederkoorn, 2015; Kahan, Polivy, \& Herman, 2003; Sellahewa \& Mullan, 2015; Vohs \& 
Heatherton, 2000). Even though we instructed our participants that they could make the puzzles at their own leisure, and it did not matter how many they would finish, we cannot exclude the possibility that participants set self-imposed goals on how many of the puzzles they wanted to complete, and perhaps felt ego-depleted by the effort they put in, or disappointed when they did not reach this goal. It would be interesting to replicate the current study with a control condition that is unlikely to elicit feelings of boredom or a need to achieve. Future studies incorporating an improved control condition could elucidate whether the observed overeating in emotional eaters is conditional on the presence of foodrelated cues, or whether the mere availability of food is a cue in itself and sufficient to induce overeating.

It has repeatedly been shown that emotional eating does not predict food intake in response to negative emotions in both student (Adriaanse, et al., 2011; Bongers, et al., 2013a; Bongers, et al., 2013b; Conner, et al., 1999; Evers, et al., 2009) and obese samples (Brogan \& Hevey, 2013). In contrast with these findings, but in line with some other studies (Raspopow, Abizaid, Matheson, \& Anisman, 2014; Van Strien, et al., 2013; van Strien, Herman, Anschutz, Engels, \& de Weerth, 2012), the current results indicate that self-reported emotional scales may have at least some predictive validity, in the sense that individuals scoring high on this measure increased their food intake when in a negative mood. However, 'emotional eating' appears to be a misleading name that does not fully capture the eating behaviour of individuals currently named 'emotional eaters'. Indeed, emotional eaters overeat after a variety of cues, not restricted to negative emotions. If future studies replicate the current findings, 'cue-reactive eaters' might be a more appropriate name for these individuals.

The current study has some limitations that should be noted. First, the sample consisted of healthy young women, and therefore the results cannot be generalized to other populations, such as individuals who seek treatment, or those who are obese or otherwise eating-disordered. The second limitation concerns the lab-setting the experiment was conducted in. It is possible that some individuals are more comfortable with eating in the lab than others, and therefore a lab-design might not accurately capture those specific individuals who overeat in response to negative emotions in real life. Third, although advertised as a study on taste perception under different circumstances, we cannot rule out the possibility that some participants were aware that we measured food intake and that this altered their behaviour. Fourth, questionnaires and behaviour can mutually influence each other. Although we aimed to minimize this effect by having participants fill out the DEBQ at the moment of study sign-up and not during one of the study sessions, we cannot exclude the possibility that filling out the questionnaire exerted some influence on eating behaviour. A final concern is the repeated taste tests in the study, 
398 both within and between sessions. It is possible that participating in taste tests in session 1 influenced 399 participants' intake during the taste tests in session 2. In the current study this seems unlikely, given the 400 finding that in the two control conditions in session 1 and session 2 intake was not significantly different. 401 With regard to taste test influences within sessions, even little intake of food during one taste test might 402 lessen hunger or could cause lesser intake in subsequent taste tests. However, because the order of 403 manipulations was fully counterbalanced, if this effect was indeed present, it should have been the 404 same for all conditions.

405 Taken together, the results of this study provide the first experimental evidence for the idea that so406 called emotional eaters increase their food intake in response to a variety of cues. This raises the 407 question whether 'emotional eating' fully captures the eating behaviour of individuals classified as 408 'emotional eaters'. 


\section{$410 \quad$ Acknowledgements}

411

412 This study is part of an ongoing project that is financed by the Netherlands Organisation for Scientific

413 Research (NWO): Vici Grant 453.10.006, awarded to Anita Jansen. We thank Angeliki-Maria Miliaraki for 414 her help with data collection.

415

416 
Adriaanse, M. A., de Ridder, D. T. D., \& Evers, C. (2011). Emotional eating: Eating when emotional or emotional about eating? Psychology \& Health, 26(1), 23-39.

Bongers, P., Jansen, A., Havermans, R., Roefs, A., \& Nederkoorn, C. (2013a). Happy eating: The underestimated role of overeating in a positive mood. Appetite, 67, 74-80.

Bongers, P., Jansen, A., Houben, K., \& Roefs, A. (2013b). Happy Eating: The Single Target Implicit Association Test predicts overeating after positive emotions. Eating Behaviors, 14, 348-355.

Bongers, P., Van den Akker, K., Havermans, R., \& Jansen, A. (submitted). Emotional eating as a case of Pavlovian learning: does negative mood facilitate appetitive conditioning?

Brogan, A., \& Hevey, D. (2013). Eating styles in the morbidly obese: restraint eating, but not emotional and external eating, predicts dietary behaviour. Psychology \& health, 28(6), 714-725.

Brondel, L., Romer, M., Van Wymelbeke, V., Pineau, N., Jiang, T., Hanus, C., et al. (2009). Variety enhances food intake in humans: role of sensory-specific satiety. Physiology \& behavior, 97(1), 44-51.

Conner, M., Fitter, M., \& Fletcher, W. (1999). Stress and snacking: A diary study of daily hassles and between-meal snacking. Psychology \& Health, 14(1), 51-63.

Evers, C., de Ridder, D. T. D., \& Adriaanse, M. A. (2009). Assessing yourself as an emotional eater: Mission impossible? Health Psychology, 28(6), 717-725.

Greeno, C. G., \& Wing, R. R. (1994). Stress-induced eating. Psychological bulletin, 115(3), 444.

Groesz, L. M., McCoy, S., Carl, J., Saslow, L., Stewart, J., Adler, N., et al. (2012). What is eating you? Stress and the drive to eat. Appetite, 58(2), 717-721.

Havermans, R. C., Vancleef, L., Kalamatianos, A., \& Nederkoorn, C. (2015). Eating and inflicting pain out of boredom. Appetite, 85, 52-57.

Herman, C. P., \& Mack, D. (1975). Restrained and unrestrained eating. Journal of Personality, 43(4), 647660.

Herman, C. P., \& Polivy, J. (1975). Anxiety, restraint, and eating behavior. Journal of abnormal psychology, 84(6), 666.

Hetherington, M. M., Foster, R., Newman, T., Anderson, A. S., \& Norton, G. (2006). Understanding variety: tasting different foods delays satiation. Physiology \& behavior, 87(2), 263-271.

Jansen, A., Nederkoorn, C., Roefs, A., Bongers, P., Teugels, T., \& Havermans, R. (2011). The proof of the pudding is in the eating: Is the DEBQ - External Eating Scale a valid measure of external eating? International Journal of Eating Disorders, 44(2), 164-168.

Kahan, D., Polivy, J., \& Herman, C. P. (2003). Conformity and dietary disinhibition: A test of the ego-strength model of self-regulation. International Journal of Eating Disorders, 33(2), 165-171.

Raspopow, K., Abizaid, A., Matheson, K., \& Anisman, H. (2014). Anticipation of a psychosocial stressor differentially influences ghrelin, cortisol and food intake among emotional and non-emotional eaters. Appetite, 74, 35-43.

Schyns, G, Roefs, A., Mulkens, S., \& Jansen, A. (2015). Expectancy violation, reduction of food cue reactivity and less eating in the absence of hunger after one food cue exposure session for overweight and obese women. Manuscript submitted for publication.

Sellahewa, D. A., \& Mullan, B. (2015). Health behaviours and their facilitation under depletion conditions: The case of snacking. Appetite, 90(0), 194-199.

Stunkard, A. J., \& Messick, S. (1985). The three-factor eating questionnaire to measure dietary restraint, disinhibition and hunger. Journal of psychosomatic research, 29(1), 71-83. 
Turner, S. A., Luszczynska, A., Warner, L., \& Schwarzer, R. (2010). Emotional and uncontrolled eating styles and chocolate chip cookie consumption. A controlled trial of the effects of positive mood enhancement. Appetite, 54(1), 143-149.

Vainik, U., Neseliler, S., Konstabel, K., Fellows, L. K., \& Dagher, A. (2015). Eating traits questionnaires as a continuum of a single concept. Uncontrolled eating. Appetite, 90(0), 229-239.

Van Strien, T. (2005). Nederlandse Vragenlijst voor Eetgedrag 2005. Handleiding en Verantwoording [Manual of the Dutch Eating Behavior Questionnaire 2005]: Amsterdam: Boom test uitgevers.

Van Strien, T., Cebolla, A., Etchemendy, E., Gutiérrez-Maldonado, J., Ferrer-García, M., Botella, C., et al. (2013). Emotional eating and food intake after sadness and joy. Appetite, 66, 20-25.

Van Strien, T., Frijters, J. E., Bergers, G. P., \& Defares, P. B. (1986). The Dutch Eating Behavior Questionnaire (DEBQ) for assessment of restrained, emotional, and external eating behavior. International Journal of Eating Disorders, 5(2), 295-315.

van Strien, T., Herman, C. P., Anschutz, D. J., Engels, R. C. M. E., \& de Weerth, C. (2012). Moderation of distress-induced eating by emotional eating scores. Appetite, 58(1), 277-284.

Van Strien, T., \& Ouwens, M. A. (2003). Counterregulation in female obese emotional eaters: Schachter, Goldman, and Gordon's (1968) test of psychosomatic theory revisited. Eating Behaviors, 3(4), 329-340.

Vohs, K. D., \& Heatherton, T. F. (2000). Self-regulatory failure: A resource-depletion approach. Psychological science, 11(3), 249-254.

Vuoskoski, J. K., \& Eerola, T. (2012). Can sad music really make you sad? Indirect measures of affective states induced by music and autobiographical memories. Psychology of Aesthetics, Creativity, and the Arts, 6(3), 204.

Wardle, J. (1990). Conditioning processes and cue exposure in the modification of excessive eating. Addictive Behaviors, 15(4), 387-393. 